\title{
ANGIOKERATOMA: A CASE REPORT
}

Divvya B ${ }^{1}$, M. Valluvan², P. Viswanathan ${ }^{3}$, P. V. S. Prasad 4 , S. Mishra ${ }^{5}$

\section{HOW TO CITE THIS ARTICLE:}

Divvya B, M. Valluvan, P. Viswanathan, P. V. S. Prasad, S. Mishra. "Angiokeratoma: A Case Report". Journal of Evolution of Medical and Dental Sciences 2014; Vol. 3, Issue 30, July 28; Page: 8461-8467,

DOI: $10.14260 /$ jemds/2014/3071

ABSTRACT: A 7 year old female had a raised rough lesion on the right knee, which was compressible. Due to cosmetic reasons, the same was excised and proved to be a case of angiokeratoma.

KEYWORDS: Vascular Nevi, Angiokeratoma.

INTRODUCTION: The neoplasms of vascular origin are mesodermal derivative which may be present from birth or can appear in early childhood; sometimes they may appear at a later stage of life. These lesions histologically may have vessels, some of which are fully developed and filled with blood and few will be presented as collection of endothelial cells.

CASE SUMMARY: A 7 year old female presented with raised plaque like lesion on the right knee. The surface had corrugated appearance and deep red to black in color; compressible.

MACROSCOPY: The specimen was $4 \mathrm{x} 1 \mathrm{~cm}$ skin covered soft tissue mass, the surface of which showed corrugated appearance. Cut section revealed tiny pores and spongy in appearance, black colored, involving the epidermis and upper dermis.

MICROSCOPY: Section revealed skin biopsy material upto deep sub-cutaneous adipose tissue level. There is hyperkeratosis, acanthosis and papillomatosis. In the areas of papillomatosis, dilated vascular channels, mostly filled with RBCs are seen. Some of the channels are occluded with thrombi. There are also few spaces filled with lymph and there is formation of granulation tissue at one focus.

There are congested vascular channels in the dermal region.

FINAL HISTOLOGICAL DIAGNOSIS: Angiokeratoma circumscriptum.

\section{DISCUSSION:}

\section{WHO CLASSIFICATION OF CUTANEOUS VASCULAR TUMORS ${ }^{1}$}

\begin{tabular}{|l|l|}
\hline BENIGN TUMORS AND TUMOR-LIKE CONDITIONS & INTERMEDIATE VASCULAR TUMORS \\
\hline Papillary endothelial hyperplasia (Masson's tumor) & Locally Aggressive \\
Reactive angioendotheliomatosis & Kaposi-like hemangioendothelioma \\
Glomeruloid hemangioma & Giant cell angioblastoma \\
Bacillary angiomatosis & Rarely metastasizing \\
Vascular ectasias & Kaposi's sarcoma \\
Nevus flammeus (salmon patch and port-wine stain) & Retiform hemangioendothelioma \\
Angiokeratoma & Papillary intravascular \\
Generalized essential telangiectasia & angioendothelioma(malignant \\
\hline
\end{tabular}




\section{CASE REPORT}

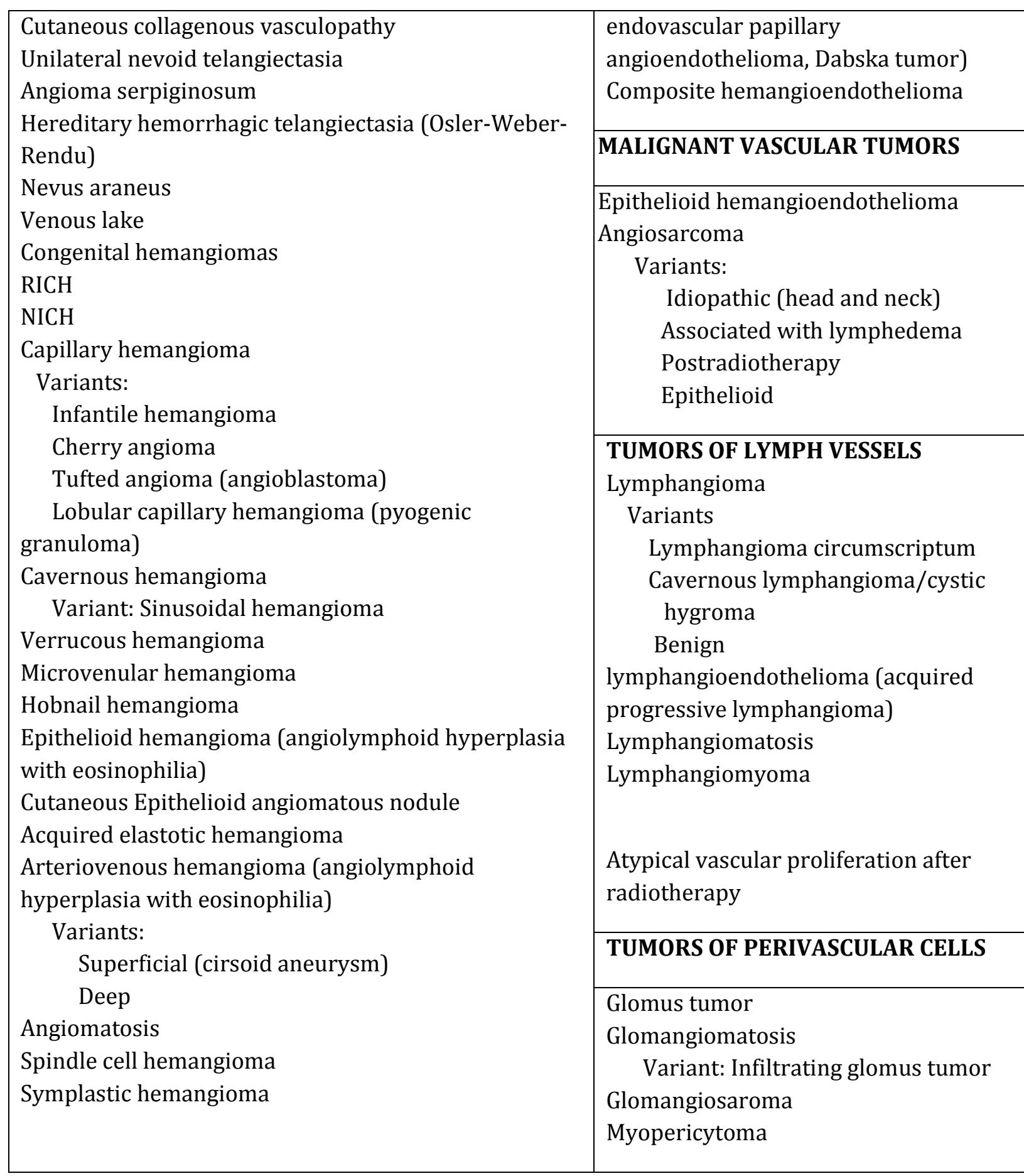

The common congenital vascular lesions of the skin are Nevus flammeus and Strawberry mark. Nevus flammeus otherwise known as Port-wine stain is a congenital vascular lesion of telangiectatic type and the other common congenital vascular lesion Strawberry mark ${ }^{2}$ is a type of capillary hemangioma. Deep-seated congenital vascular lesions will most commonly be of cavernous type.

Bartonellosis (Verruca peruana) simulate hemangioma, but the organism can be found in the endothelial cells. ${ }^{3}$ 
The common vascular lesions that can occur in the upper dermis, involving the epidermis are Angiokeratoma and Lymphangioma circumscriptum.

\section{ANGIOKERATOMA CAN BE CLASSIFIED AS:}

ANGIOKERATOMA CORPORIS DIFFUSUM: Patients present with numerous clusters of tiny red papules in a symmetrical distribution usually in the bathing-trunk area. ${ }^{1}$

ANGIOKERATOMA OF MIBELLI: Usually appearing during childhood or adolescence, several dark red papules with a slightly verrucous surface are seen on the dorsa of the fingers and toes measuring 3 to $5 \mathrm{~mm}$ in diameter. ${ }^{1}$

ANGIOKERATOMA OF FORDYCE: Multiple vascular papules 2 to $4 \mathrm{~mm}$ in diameter are seen on the scrotum. They arise in middle or later life. Early lesions are red, soft, and compressible; later, they become blue, keratotic, and non-compressible. ${ }^{1}$

SOLITARY OR MULTIPLE ANGIOKERATOMAS: Usually one and occasionally several papular lesions arise in young adults, most commonly on the lower extremities. The lesions range from 2 to $10 \mathrm{~mm}$ in diameter. Early lesions appear bright red and soft, but they later become blue to black, firm, and hyperkeratotic. ${ }^{4}$

HISTOPATHOLOGY: The histologic findings are essentially the same in all four above-mentioned types of angiokeratoma.

It consists of numerous, dilated, thin-walled, congested capillaries mainly in the papillary dermis underlying an epidermis that shows variable degrees of acanthosis with elongation of the rete ridges and hyperkeratosis. ${ }^{4}$

LYMPHANGIOMA CIRCUMSCRIPTUM: Lymphangioma circumscriptum is predominantly a developmental malformation of infancy with an equal gender incidence, but it may arise at any age. The proximal portions of the limbs and limb girdle are most frequently affected. Association with cavernous lymphangioma, cystic hygroma, and even lymphangiomatosis is common. ${ }^{1}$

A typical lesion consists of collections of numerous vesicles containing clear fluid and less commonly, blood. Due to the presence of a deep component, lesions arising in infancy tend to recur after simple excision. ${ }^{1}$

HISTOPATHOLOGY: Lymphangioma circumscriptum is composed of numerous dilated lymphatics in the superficial and papillary dermis. There is clear fluid and, less frequently, red blood cells in their lumina. In the overlying epidermis there is some degree of acanthosis and hyperkeratosis.

The surrounding stroma shows scattered lymphocytes. Lesions developing in infancy often show a large-caliber, muscular lymphatic space in the subcutaneous tissue, which has to be ligated at the time of excision to avoid recurrence. ${ }^{1}$ 


\section{CASE REPORT}

\section{REFERENCES:}

1. Walter F. Lever. Histopathology of the skin: In: David E Elder, Rosalie Elenitsas, Bernett L. Johnson, George F. Murphy eds. Lever's Histopathology of the skin., Lipincott Williams \& Wilkins, Tenth edn, 2009: 1008 - 11

2. Madusa M. A histological and electron microscopical study on strawberry nevus (strawberry mark). Jpn J Dermatol [B] 81: 104, 1971

3. Arona G, Small 0. Verruga peruana o enfermedad de carrion. Dermatologia, Revista Mexicana 18: 20,1974

4. Schiller PI, Itin PH. Angiokeratomas: an update. Dermatology 1996; 193: 275.

\section{MACROSCOPIC IMAGES}
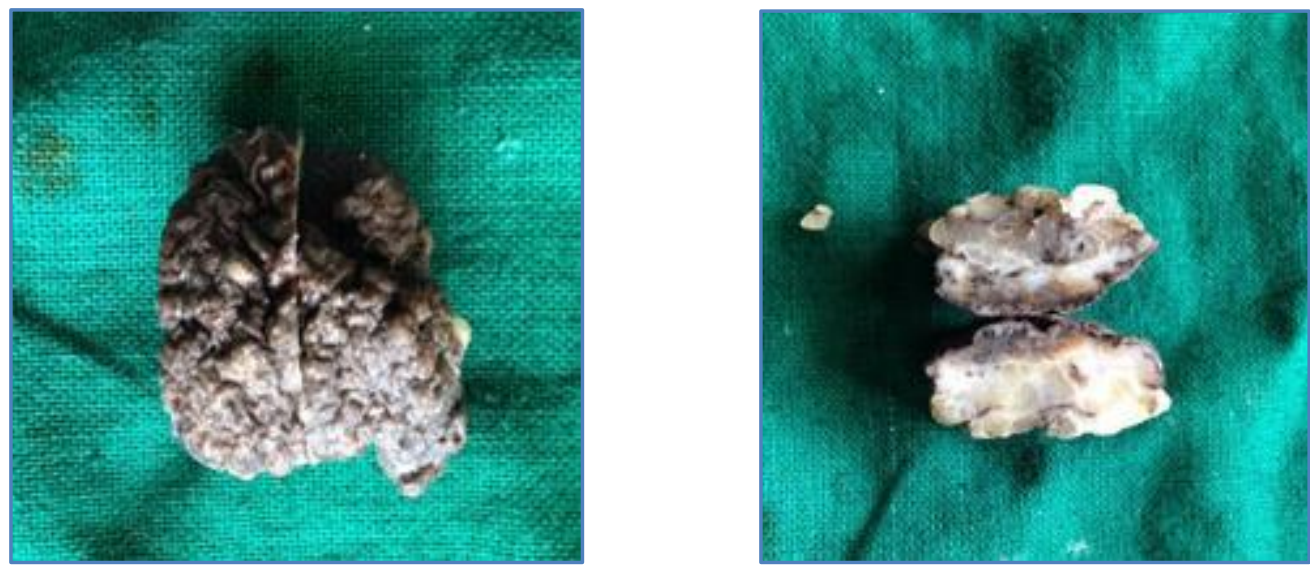

\section{MICROSCOPIC IMAGES}

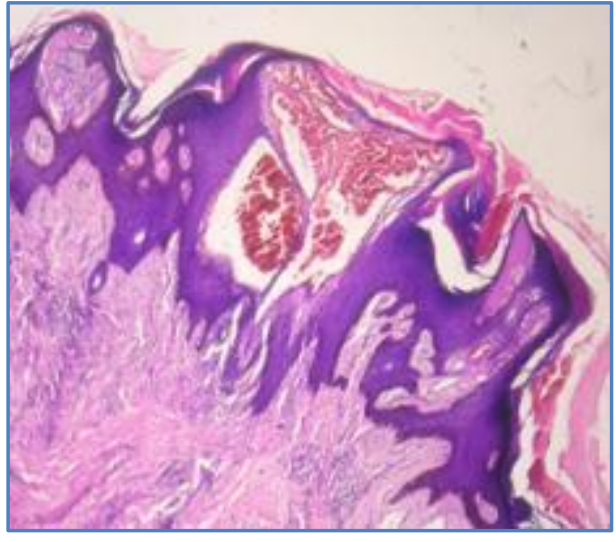

Fig. 1A: H \& E stained $4 x$

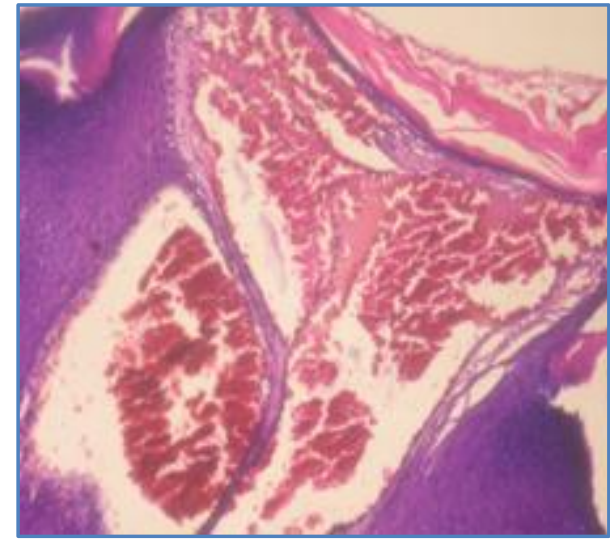

Fig. 1B: H \& E stained $10 x$

Showing dilated blood vessels in the epidermal zone which is lined by endothelial cells. 


\section{CASE REPORT}

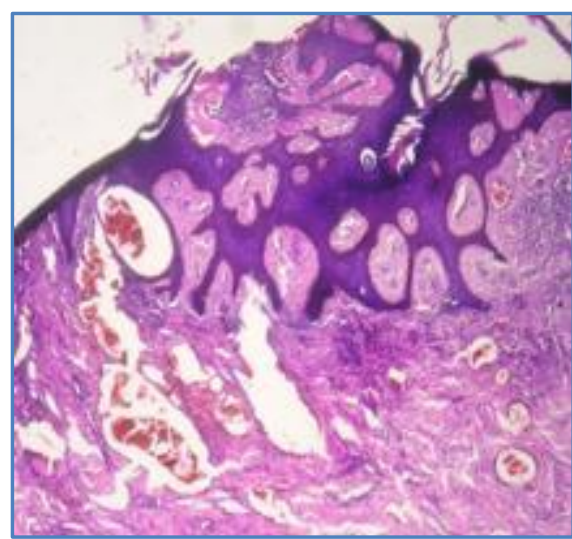

Fig. 2A: H \& E stained 4 x

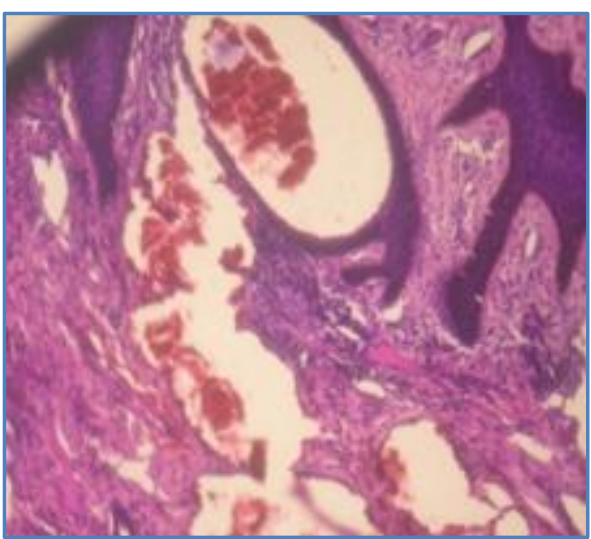

Fig. 2B: H \& E stained $10 \mathrm{x}$

Showing dilated blood vessels filled with RBCs in the upper dermis. Also seen are telengectic spaces.

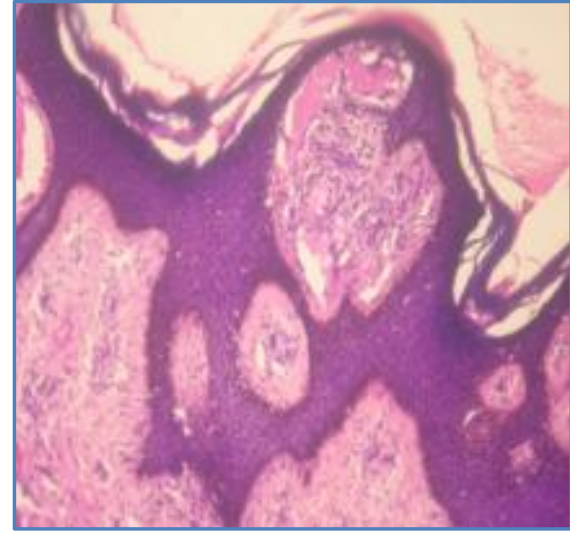

Fig. 3A: H \& E stained $10 x$

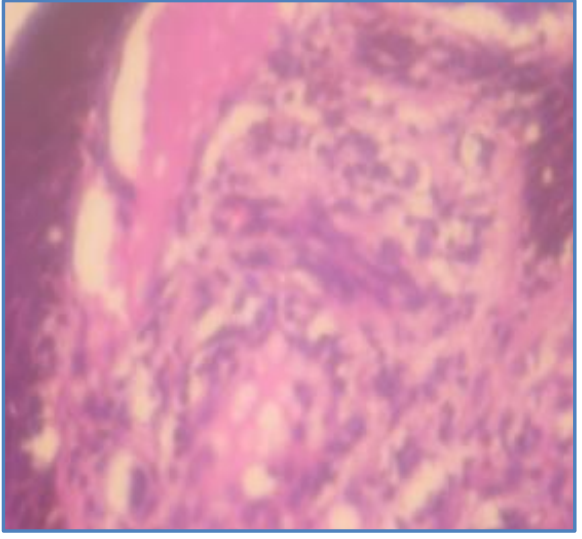

Fig. 3B: H \& E stained $40 x$

Dilated space filled with granulation tissue located in the epidermis.

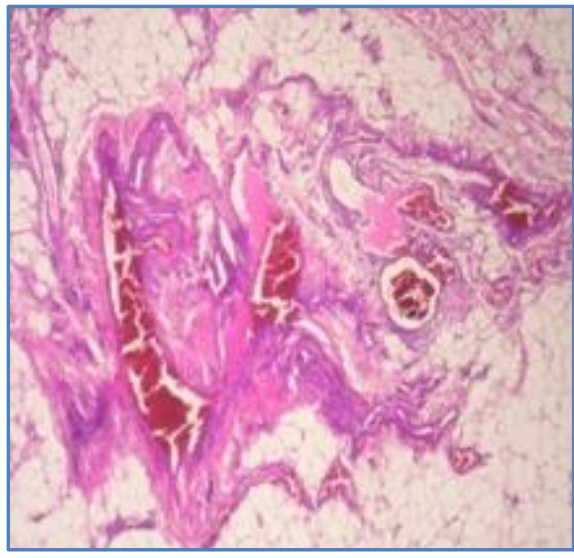

Fig. 4A: H \& E stained $4 x$

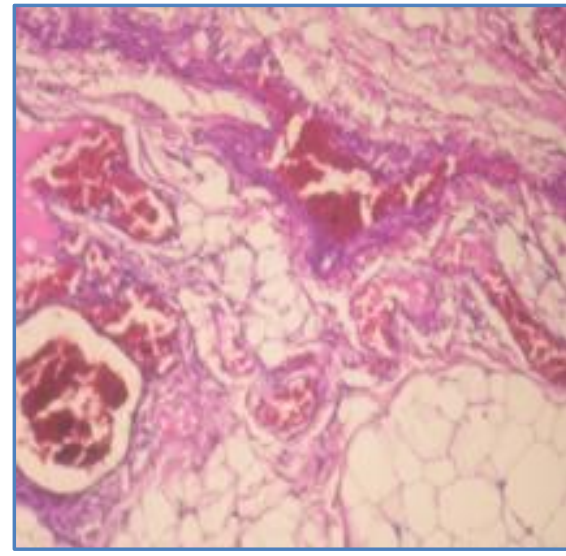

Fig. 4B: H \& E stained $10 x$

Dilated vascular spaces many filled with RBCs and few filled with lymph present in the deep sub-cutaneous adipose tissue level. 


\section{CASE REPORT}

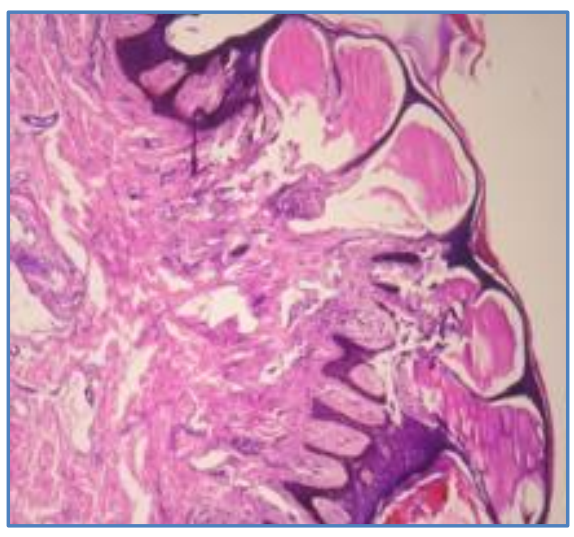

Fig. 5A: H \& E stained $4 x$

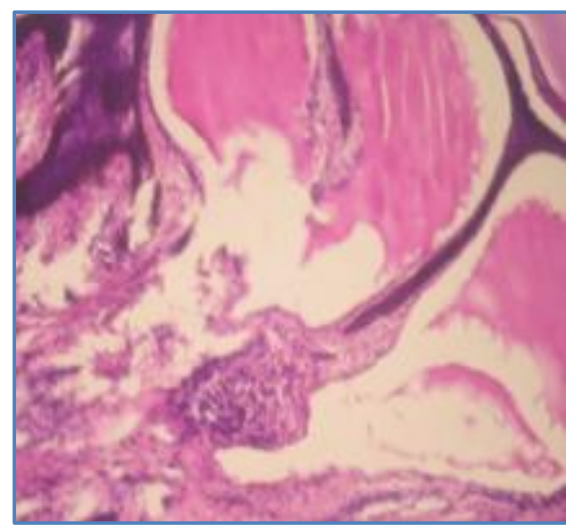

Fig. 5B: H \& E stained $10 x$

Raised plaque-like lesion present in the upper dermal region; lined vascular spaces filled with lymph and few spaces filled with RBCs.

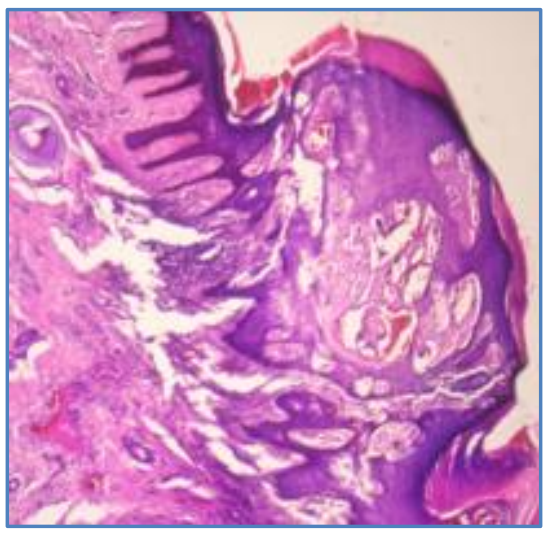

Fig. 6A: H \& E stained $4 x$

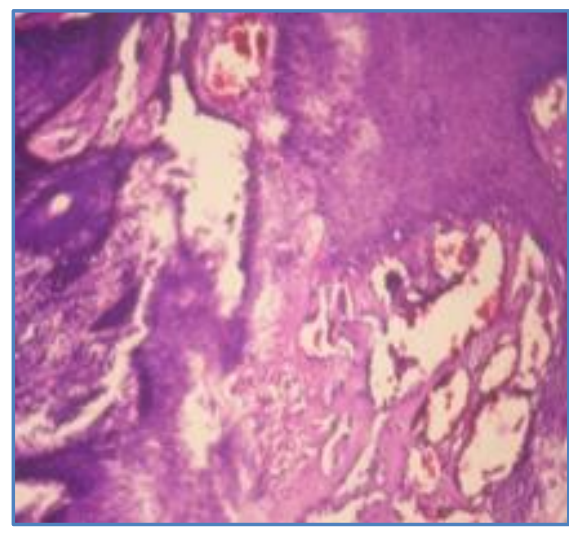

Fig. 6B: H \& E stained $10 x$

Raised plaque-like lesion, where telengectic spaces present in the epidermis. Dilated vascular channels present in the upper dermal region.

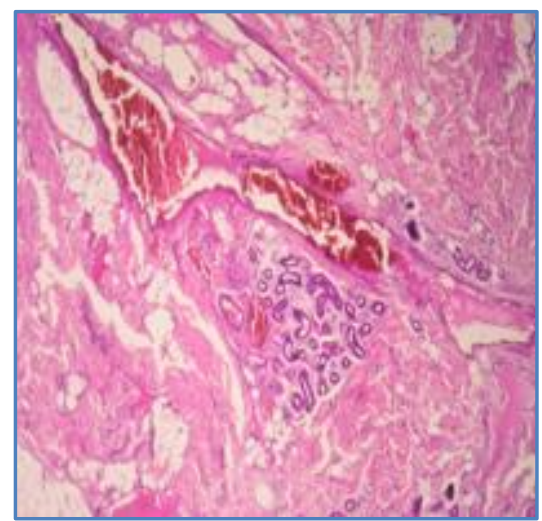

Fig. 7A: H \& E stained $4 \mathrm{x}$

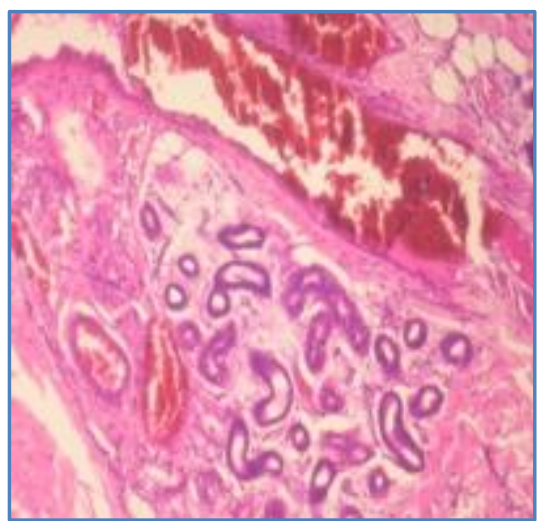

Fig. 7B: H \& E stained $10 x$

Dilated vascular channel in mid-dermal zone filled with RBCs. 


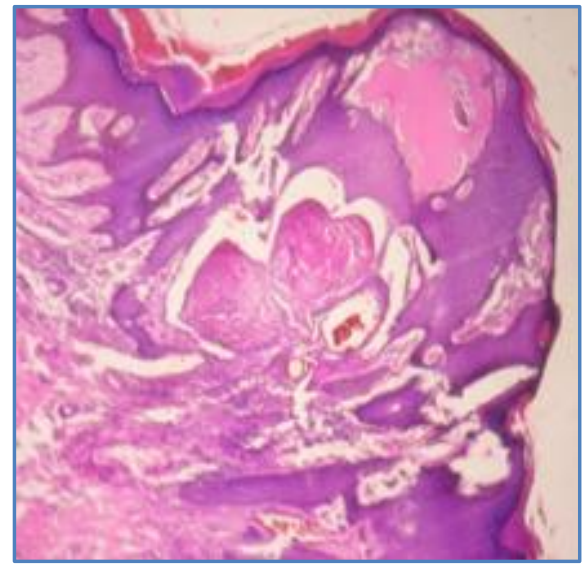

Fig. 8A: H \& E stained $4 \mathrm{x}$

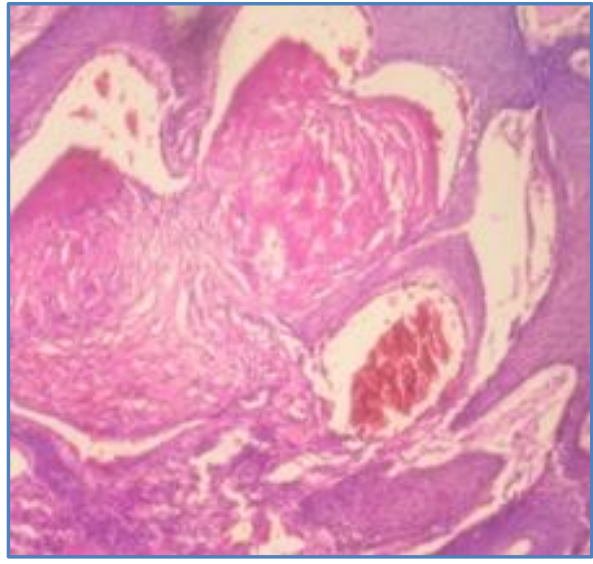

Fig. 8B: H \& E stained $10 \mathrm{x}$

Plaque-like lesion, where the space is filled with recent thrombus.

\section{AUTHORS:}

1. Divvya B.

2. M. Valluvan

3. P. Viswanathan

4. P. V. S. Prasad

5. S. Mishra

\section{PARTICULARS OF CONTRIBUTORS:}

1. $2^{\text {nd }}$ Year Post Graduate, Department of Pathology, Rajah Muthiah Medical College, Annamalai University.

2. $2^{\text {nd }}$ Year Post Graduate, Department of Pathology, Rajah Muthiah Medical College, Annamalai University.

3. Professor, Department of Pathology, Rajah Muthiah Medical College, Annamalai University.

4. Professor, Department of Dermatology Venereology and Leprosy, Rajah Muthiah Medical College, Annamalai University.
5. Professor, Department of Plastic Surgery, Rajah Muthiah Medical College, Annamalai University.

\section{NAME ADDRESS EMAIL ID OF THE CORRESPONDING AUTHOR:}

Dr. P. Viswanathan,

Professor,

Department of Pathology,

Rajah Muthiah Medical College,

Annamalai University,

Chidambaram-608002,

Tamilnadu, India.

Email: drpviswanathan2013@gmail.com

Date of Submission: 13/07/2014.

Date of Peer Review: 14/07/2014.

Date of Acceptance: 19/07/2014.

Date of Publishing: 25/07/2014. 